\title{
OPEN Simultaneous quantitative profiling of clinically relevant immune markers in neonatal stool swabs to reveal inflammation
}

\author{
Veronika Vidova, Eliska Benesova, Jana Klanova, Vojtech Thon \& Zdenek Spacil ${ }^{\bowtie}$
}

An aberrant immune response developed early in life may trigger inflammatory bowel disease (IBD) and food allergies (e.g., celiac disease). Fecal levels of immune markers categorize an inflammatory response (e.g., food allergy, autoimmune) paralleled with the initial microbial colonization. The immunoaffinity assays are routinely applied to quantify circulating immune protein markers in blood/serum. However, a reliable, multiplex assay to quantify fecal levels of immune proteins is unavailable. We developed mass spectrometry assays to simultaneously quantify fecal calprotectin, myeloperoxidase, eosinophil-derived neurotoxin, eosinophil cationic protein, alpha-1-antitrypsin 1, and adaptive immunity effectors in 134 neonatal stool swabs. We optimized extraction and proteolytic protocol and validated the multiplex assay in terms of linearity of response ( $>100$; typically 0.04 to $14.77 \mu \mathrm{g} / \mathrm{mg}$ of total protein), coefficient of determination $\left(R^{2} ;>0.99\right)$, the limit of detection (LOD; 0.003 to $0.04 \mu \mathrm{g} / \mathrm{mg}$ of total protein), the limit of quantification (LOQ; 0.009 to $0.122 \mu \mathrm{g} / \mathrm{mg}$ of total protein) and robustness. The median CV of intra- and interday precision was $9.8 \%$ and $14.1 \%$, respectively. We quantified breast milk-derived IGHA2 to differentiate meconium from feces samples and to detect the first food intake. An early life profiling of immune markers reflects disrupted intestinal homeostasis, and it is perhaps suitable for pre-symptomatic interception of IBD and food allergies.

Inflammatory bowel disease (IBD) and food allergies are a highly prevalent and diverse group of intestinal disorders, potentially resulting in chronic inflammation of the gastrointestinal tract (e.g., Crohn's disease, ulcerative colitis, and celiac diseases). IBD is an umbrella term for disorders with unknown etiology affecting 6.8 million people globally ${ }^{1}$. In Western countries, as high as $10 \%$ of the population reacts abnormally to a food allergen, with the highest prevalence among younger children ${ }^{2}$. The global prevalence of celiac disease was $1.4 \%$, significantly greater in children than adults ${ }^{3}$. However, specific causes of food allergies are challenging to explore, and the prevalence is likely underreported ${ }^{4,5}$.

The early life or even prenatal exposure of the naïve immune system to human gut microbiota plays a prominent role in immunomodulation, potentially resulting in an inappropriate immune response and disorders ${ }^{6,7}$. The mode of delivery (i.e., cesarean section or vaginal birth), nutritional and lifestyle factors (e.g., breastfeeding, hygiene, probiotics), or medication (e.g., antibiotics) shapes the composition of the human gut microbiota, influencing the response of the immature immune system and homeostasis ${ }^{8-10}$. Naturally-born neonates benefit from early colonization by the vaginal microbiome ${ }^{11,12}$. On the contrary, adverse influence is attributed to the early colonization by nosocomial or skin microbiota after cesarean section ${ }^{13,14}$. Breastfeeding reportedly prevents allergies, asthma, and infections ${ }^{15}$. Mucosal immunoglobulins, prebiotics, and other breast milk components protect against disease and allergies via modulation of developing immune system and intestinal barrier function. Mucosal epithelial cells are arranged into a tight junctional complex during intestinal maturation and later form the permeable barrier between the intestinal lumen and the lamina propria ${ }^{16}$. In autoimmune diseases, the presence of allergens and pathogens causes intestinal inflammation and disruption of epithelial cells. Neutrophils, monocytes, eosinophils, white blood cells, and blood protein occur in the stool due to the intestinal barrier's lower integrity, causing inflammation.

The naïve immune system's inflammatory response traced via specific immunological markers in meconium or first feces can reveal a disease condition. Fecal calprotectin (CAL1, CAL2) and myeloperoxidase (MPO) 


\begin{tabular}{|l|l|l|l|l|}
\hline Protein number & Gene name & Name & Abbreviation & Proteotypic sequence \\
\hline P01009-1 & SERPINA1 & Alpha-1-antitrypsin isoform 1 & A1AT-1 & AVLTIDEK \\
\hline P01876 & IGHA1 & Immunoglobulin heavy constant alpha 1 & IGHA1 & TPLTATLSK \\
\hline P01876+ P01877 & IGHA1 +2 & Immunoglobulin heavy constant alpha 1 and 2 & IGHA1 +2 & SAVQGPPER \\
\hline P01877 & IGHA2 & Immunoglobulin heavy constant alpha 2 & IGHA2 & DASGATFTWTPSSGK \\
\hline P12724 & RNASE3 & Eosinophil cationic protein & ECP & NQNTFLR \\
\hline P10153 & RNASE2 & Eosinophil-derived neurotoxin & EDN & DPPQYPVVPVHLDR \\
\hline P05164 & MPO & Myeloperoxidase & MPO & VVLEGGIDPILR \\
\hline P05109 & S100-A8 & Calprotectin 1 & CAL1 & ALNSIDVYHK \\
\hline P06702 & \multirow{2}{*}{ S100-A9 } & Calprotectin 2 & \multirow{2}{*}{ CAL2 } & DLQNFLK \\
& & & & LGHPDTLNQGEFK \\
\hline
\end{tabular}

Table 1. Immune protein markers were assayed in meconium and feces. The proteotypic surrogate peptides for absolute quantification. The position of stable isotope-labeled arginine $\left(\mathrm{R}^{*} ;{ }^{13} \mathrm{C}_{6} \mathrm{H}_{14} \mathrm{O}_{2}{ }^{15} \mathrm{~N}_{4} ;+10\right.$ Da mass shift) or lysine $\left(\mathrm{K}^{*} ;{ }^{13} \mathrm{C}_{6} \mathrm{H}_{14} \mathrm{O}_{2}{ }^{15} \mathrm{~N}_{2} ;+8 \mathrm{Da}\right.$ mass shift $)$ in the proteotypic sequence of internal standard synthetic peptides marked in bold.

indicate neutrophilic inflammation (i.e., pathogen-induced response, autoimmune reaction). Calprotectin levels in adult patients correspond with the progression from irritable bowel syndrome (IBS) to chronic IBD ${ }^{17}$. Fecal MPO in adults is reportedly a parameter of $\mathrm{IBD}^{18}$ and ulcerative colitis severity ${ }^{19}$. The correlation between calprotectin and MPO in neonates was demonstrated ${ }^{20}$. Fecal eosinophil-derived neurotoxin (EDN) and eosinophil cationic protein (ECP) are often seen in a patient with food allergic colitis and typically present in children with an atopic family history before the age of two years ${ }^{21}$. High alpha 1-antitrypsin 1 (A1AT-1) and immunoglobulin A1 (IGHA1) levels point to the disrupted intestinal barrier function in toddlers ${ }^{22}$. The analysis of inflammatory markers in a neonatal cohort can perhaps later provide information on IBD and allergy development. Fecal immunoglobulin A2 (IGHA2) derived from breast milk distinguishes meconium from the first feces ${ }^{23}$ to assess the nutritional influence on the colonization by intestinal microbiota.

Serum ECP levels determined by immunoassays ${ }^{24}$ are diagnostic for eosinophil inflammatory activity in asthma and allergies to estimate disease severity. Fecal ECP, EDN, and MPO are typically quantified in radioimmunoassay or enzyme-linked immunosorbent assay (ELISA) ${ }^{25}$. Skarzynska et al. applied ELISA to quantify MPO in the meconium of healthy neonates $(n=80)$ and determined concentrations between 0.02 and $8.8 \mu \mathrm{g} / \mathrm{g}$ of meconium, an average of $1.8 \mu \mathrm{g} / \mathrm{g}^{26}$. Roca et al. determined the average concentration of fecal EDN and calprotectin at $7.4 \mu \mathrm{g} / \mathrm{g}$ and $910.3 \mu \mathrm{g} / \mathrm{g}$ in 174 healthy toddlers $(0-12 \mathrm{months})^{27}$. Clinically relevant calprotectin levels are qualified via ELISA ${ }^{28}$ and A1AT levels via nephelometry ${ }^{29}$ in feces. Meconium A1AT levels determined in 19 healthy neonates were $3720 \mu \mathrm{g} / \mathrm{g}$ on average $\mathrm{e}^{30}$. The quantification of fecal immunoglobulin A employs radial immunodiffusion or ELISA ${ }^{31,32}$. Meconium A1AT decreases, and immunoglobulin A content increases within the initial days of life ${ }^{32}$.

Our study presents the multiplex quantification of inflammatory proteins in stool using ultra-high-performance liquid chromatography (UHPLC) and tandem mass spectrometry (MS/MS) in selected reaction monitoring (SRM) mode. The concept of UHPLC-SRM targeted proteomics is widely applicable in science, with clear advantages over immunoaffinity assays ${ }^{33-36}$. We are the first to present an SRM proteomics protocol for absolute quantification in neonatal meconium and feces swabs. The application towards a panel of clinically relevant markers (Table 1) reflecting the intestinal mucosal barrier homeostasis. The multiplex assay is suitable for classifying

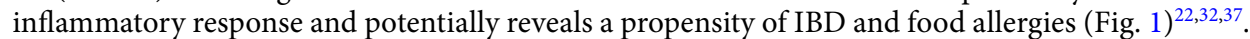

\section{Methods}

Chemicals. Proteotypic peptides selected as protein surrogates are in Table 1. Stable isotopically labeled (SIL) peptide standards with C-terminal arginine $\left(\mathrm{R}^{\star} ;{ }^{13} \mathrm{C}_{6} \mathrm{H}_{14} \mathrm{O}_{2}{ }^{15} \mathrm{~N}_{4} ;+10 \mathrm{Da}\right.$ mass shift) or lysine ( $\mathrm{K}^{\star}$; ${ }^{13} \mathrm{C}_{6} \mathrm{H}_{14} \mathrm{O}_{2}{ }^{15} \mathrm{~N}_{2}$; 8 Da mass shift) were custom synthesized (SpikeTides ${ }^{\mathrm{Tx}} \mathrm{L}$ and TQL, JPT Technologies, Berlin, Germany). We used SIL peptides (SpikeTides ${ }^{\mathrm{TN}} \mathrm{L}$ ) for assay development and optimization. SIL synthetic peptides extended at C-terminus with a trypsin cleavable tag (SIL-TCT, SpikeTides ${ }^{\text {Tx }}$ TQL) were used as internal standards for protein quantification. The trypsin cleavable tag consists of a tetrapeptide that incorporates a nitrotyrosine residue ${ }^{38}$. Sequences of all proteotypic peptides used for protein quantification are in Tables 1 and 2. Trypsin gold was from Promega (cat. \#V5280). LC-MS grade acetonitrile (ACN, cat. \#00136878) and isopropyl alcohol (IPA, cat. \#16267802) was from Biosolv (Valkenswaard, The Netherlands). Formic acid (FA, cat. \#94318), ammonium bicarbonate (ABB, $\geq 99.5 \%$; cat. \#09830), iodoacetamide (IAA, cat. \#I6125), and sodium deoxycholate (SDC, $\geq 98 \%$; cat. \#30970) were from Sigma Aldrich (St. Louis, MO). Dithiothreitol (DTT, cat. \#20290) and BCA protein assay kit (cat. \#23225) were from Thermo Fisher Scientific (Waltham, MA). The deionized water was produced in Simplicity 185 ultrapure water system (Merck Millipore corp. Billerica, MA).

Meconium and feces swabs. Under the Declaration of Helsinki, the study was approved by the Committee for Ethics of CELSPAC: TNG (CELSPAC/EK/4/2016) at University Hospital Brno, the Czech Republic. The methods used in the study and described below were carried out following the relevant guidelines and regulations. The authors confirm that the data supporting this study's findings are available within the article and sup- 


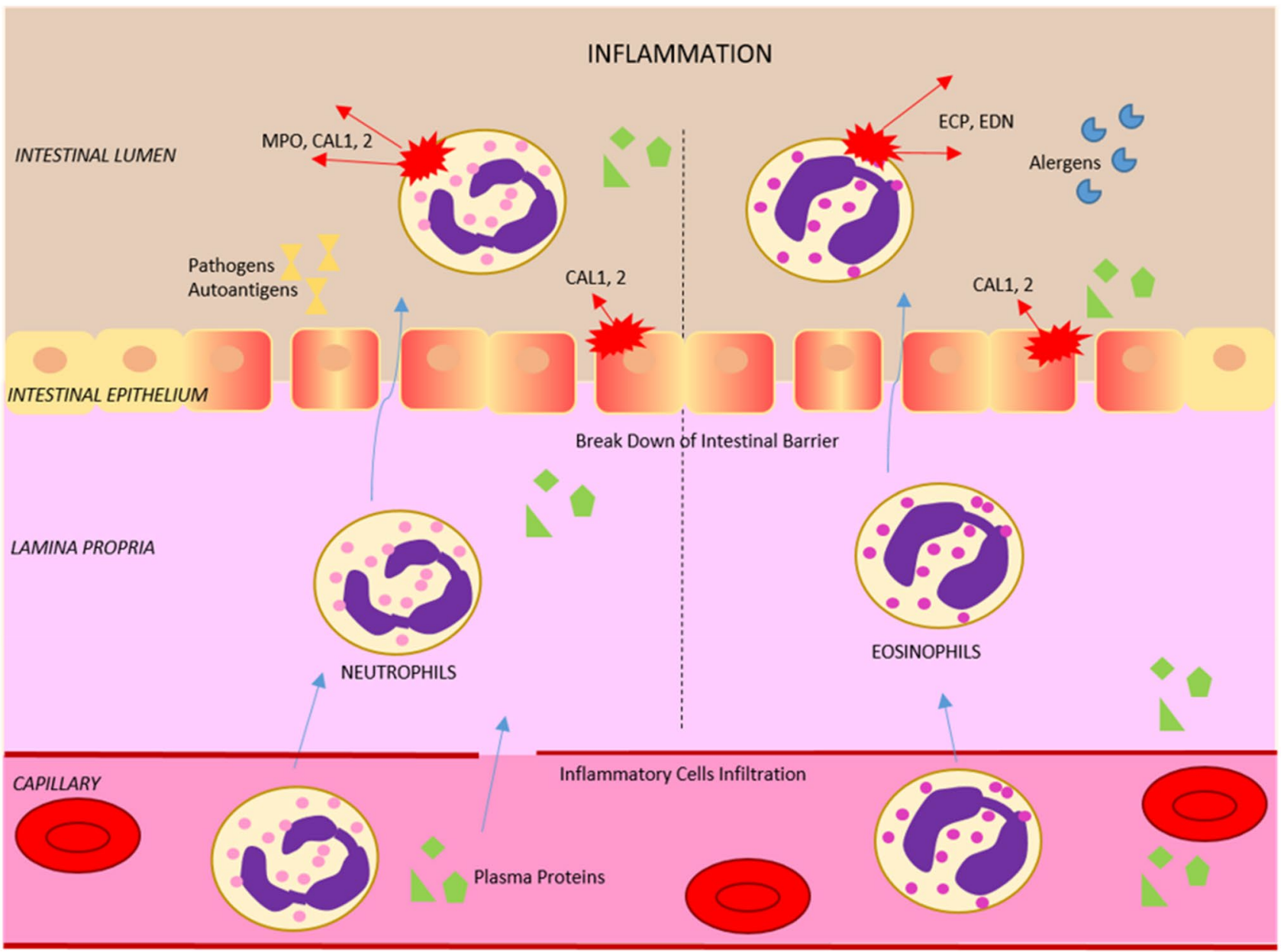

Figure 1. Scheme of immune protein markers' role in the intestinal inflammatory response, barrier function, and homeostasis.

\begin{tabular}{|c|c|c|c|c|c|c|c|c|c|c|}
\hline \multirow[b]{2}{*}{ Protein } & \multirow{2}{*}{$\begin{array}{l}\text { Internal standard peptide } \\
\text { sequence }\end{array}$} & \multirow{2}{*}{$\begin{array}{l}\text { Concentration added to sample } \\
(\mathbf{n M})\end{array}$} & \multirow[b]{2}{*}{$\mathbf{R}^{2}$} & \multicolumn{2}{|l|}{ LOD } & \multicolumn{2}{|l|}{ LOQ } & \multicolumn{2}{|l|}{ Range } & \multirow[b]{2}{*}{ Calibration levels } \\
\hline & & & & $(\mu \mathrm{g} / \mathrm{mg})$ & $(\mathbf{n M})$ & $(\mu \mathrm{g} / \mathrm{mg})$ & $(\mathbf{n M})$ & $(\mu \mathrm{g} / \mathrm{mg})$ & $(\mathbf{n M})$ & \\
\hline A1AT-1 & AVLTIDEK & 100 & 0.992 & 0.003 & 0.20 & 0.009 & 0.62 & $0.01-28.27$ & $1-2000$ & 7 \\
\hline IGHA1 & TPLTATLSK & 100 & 0.997 & 0.010 & 0.86 & 0.030 & 2.62 & $0.05-22.77$ & $4-2000$ & 9 \\
\hline IGHA1 + 2 & SAVQGPPER & 100 & 0.991 & 0.024 & 2.10 & 0.071 & 6.35 & $0.04-22.45$ & $4-2000$ & 9 \\
\hline IGHA2 & DASGATFTWTPSSGK & 120 & 0.998 & 0.037 & 3.31 & 0.111 & 10.04 & $0.11-22.13$ & $10-2000$ & 7 \\
\hline ECP & NQNTFLR & 100 & 0.999 & 0.004 & 0.69 & 0.012 & 2.08 & $0.02-3.89$ & $4-700$ & 7 \\
\hline EDN & DPPQYPVVPVHLDR & 100 & 0.993 & 0.014 & 2.58 & 0.043 & 7.81 & $0.02-3.33$ & $4-600$ & 8 \\
\hline MPO & VVLEGGIDPILR & 100 & 0.998 & 0.040 & 1.63 & 0.122 & 4.93 & $0.10-49.39$ & $4-2000$ & 7 \\
\hline CAL1 & ALNSIIDVYHK & 100 & 0.991 & 0.005 & 1.39 & 0.014 & 4.22 & $0.03-6.55$ & $10-2000$ & 8 \\
\hline \multirow{2}{*}{ CAL2 } & DLQNFLK & 100 & 0.991 & 0.007 & 1.77 & 0.020 & 5.37 & $0.04-7.40$ & $10-2000$ & 8 \\
\hline & LGHPDTLNQGEFK & 100 & 0.995 & 0.037 & 9.96 & 0.112 & 30.17 & $0.04-7.40$ & $10-2000$ & 6 \\
\hline
\end{tabular}

Table 2. The validation parameters of assessed proteotypic peptides, i.e., the linearity of response, assay range, $\mathrm{LOD}$, and LOQ. All concentrations in (nM) for peptide surrogates and in (ug/mg) for target protein in total protein (by BCA). The position of stable isotope-labeled arginine $\left(\mathrm{R}^{*} ;{ }^{13} \mathrm{C}_{6} \mathrm{H}_{14} \mathrm{O}_{2}{ }^{15} \mathrm{~N}_{4} ;+10\right.$ Da mass shift) or lysine $\left(\mathrm{K}^{*} ;{ }^{13} \mathrm{C}_{6} \mathrm{H}_{14} \mathrm{O}_{2}{ }^{15} \mathrm{~N}_{2} ;+8 \mathrm{Da}\right.$ mass shift $)$ in the proteotypic sequence of internal standard synthetic peptides marked in bold. 
plementary materials. Informed consent was obtained from a parent and/or legal guardian for all study participants and archived. The cohort study included only singleton pregnancies. Trained hospital personnel collected feces swabs from neonates $(n=134)$ during the first, second, or third day following the birth using FLOQSwabs (cat. \#520CS01, Copan, Italy). Meconium or feces were scooped up from a conventional diaper using a swab, then the swab was placed inside a $2 \mathrm{ml}$ vial, and the handle was broken off. The vial was sealed, immediately placed in a $-80^{\circ} \mathrm{C}$ freezer, and stored until pre-analytical sample processing and analysis. The study subjects were female $(n=56)$ and male $(n=78)$ neonates at gestation age (weeks + days) ranging from $38+2$ to $41+3$. An average birth weight $(\mathrm{g}) 4394.1 \pm 427.0$ SD ranged from 2470 to $4900 \mathrm{~g}$. Samples were from neonates delivered vaginally $(n=114)$ or via cesarean section $(n=20)$. Demographic and clinical characteristics of all study subjects and information on sample collection are listed in Table S1.

Protein extraction protocol. We precipitated proteins by adding $1 \mathrm{ml}$ of $80 \%$ IPA to the sample and orbital shaking $(5 \mathrm{~min}, 1600 \mathrm{rpm})$. We centrifuged samples $(2 \mathrm{~min}, 12,000 \times \mathrm{g})$ and removed $50 \mu \mathrm{L}$ of supernatant. The residual sample volume $(950 \mu \mathrm{L})$, including the swab, was dried in speed vac overnight (minimum $6 \mathrm{~h}$ ). Dried samples were reconstituted in $1500 \mu \mathrm{L}$ of buffer ( $50 \mathrm{mM} \mathrm{ABB}$ with $5 \mathrm{~g} / \mathrm{l} \mathrm{SDC}$ ) and homogenized (Benchmark Scientifics, Bead Blaster 24 homogenizer, 4 pulses $\times 30 \mathrm{~s} ; 4 \mathrm{~m} / \mathrm{s}$; inter-time $10 \mathrm{~s}$; ambient temperature). Next, we centrifuged samples $(3000 \times \mathrm{g} ; 10 \mathrm{~min})$, transferred a supernatant $(500 \mu \mathrm{L})$ into a clean vial, and centrifuged the vial again $(12,000 \times \mathrm{g} ; 5 \mathrm{~min})$. After the second centrifugation, the supernatant $(400 \mu \mathrm{L}) \mathrm{was}$ transferred into another clean vial for the trypsin digestion of extracted proteins. Total protein concentration in 134 neonatal meconium or feces swabs extracts (Table S2) were assessed in $10 \mu \mathrm{L}$ of protein extract using the BCA assay (cat. \#23225). We subjected the protein extract $(50 \mu \mathrm{L})$ to the trypsin digestion protocol.

Sample fresh weight total protein content. We prepared quality control (QC) material pooling fresh meconium and feces samples from 12 randomly selected neonates. Various QC material amounts were accurately weighed $(25,50,75,100,125,150 \mathrm{mg})$ on a swab in triplicate. We extracted proteins from feces swabs as described above and determined the protein content in protein extracts using the BCA assay (Table S3). We established the correlation between the stool sample fresh weight and total protein content and used QC swabs for method validation and reproducibility assessment.

Trypsin proteolytic protocol. We reduced and alkylated protein extracts $(50 \mu \mathrm{L})$ by adding $5 \mu \mathrm{L}$ of $200 \mathrm{mM}$ DTT $\left(10 \mathrm{~min}\right.$ at $\left.95^{\circ} \mathrm{C}\right)$ and consequently adding $5 \mu \mathrm{L}$ of $400 \mathrm{mM} \mathrm{IAA}(30 \mathrm{~min}$ at ambient temperature in the dark). We added a working solution $(10 \mu \mathrm{L} ; 500-600 \mathrm{nM})$ of the SIL-TCT peptide internal standards into a sample. Next, we added trypsin $(3 \mu \mathrm{L} ; 1 \mu \mathrm{g} / \mu \mathrm{L})$ approximately in the ratio of 1:70 to the total protein content and incubated samples at $37^{\circ} \mathrm{C}$ (orbital shaking $200 \mathrm{rpm}$ ). We quenched the trypsin digestion after $5 \mathrm{~h}$ by adding $200 \mu \mathrm{L}$ of $2 \%$ FA and peptides were purified using solid-phase extraction (SPE, Oasis HLB prime; 96-well plate format, $30 \mathrm{mg}$; Waters, Milford, MA). Samples were loaded on SPE, washed with $300 \mu \mathrm{L}$ of $2 \% \mathrm{FA}$, and eluted with $200 \mu \mathrm{L} 50 \%$ ACN with $2 \%$ FA. SPE eluates were dried in speed vac, reconstituted in $50 \mu \mathrm{L} 5 \%$ ACN with $0.1 \%$ FA, resulting in 100-120 nM SIL-TCT internal standard concentrations in the sample (Table 2), and analyzed by UHPLC/SRM-MS.

Proteolysis time optimization. Protein extracts from individually extracted QC swabs $(\mathrm{n}=3)$ were combined $(1200 \mu \mathrm{L})$ and divided into 21 identical aliquots $(50 \mu \mathrm{L})$ to prepare the time-lapse experiment in triplicate. We did not add trypsin to samples without incubation (time $0 \mathrm{~h}$ ), spiked with proteotypic SIL peptides (added $10 \mu \mathrm{L}$ of $1.5 \mu \mathrm{M}$ mixed working solution, all proteotypic sequences listed in Table 1). Trypsin was added to all incubated samples, spiked with SIL-TCT internal standards (all proteotypic sequences listed in Table 1). We quenched the trypsin digestion after $1,3,5,17,20$, and $24 \mathrm{~h}$ of incubation. The $2 \% \mathrm{FA}(200 \mu \mathrm{L})$ was added to all samples, followed by SPE processing and UHPLC/SRM-MS analysis. The reproducibility of trypsin digestion was tested using SIL-TCT peptides SAVQGPPER, DASGATFTWTPSSGK, TPLTATLSK, AVLTIDEK, DLQNFLK, LGHPDTLNQGEFK, ALNSIIDVYHK, DPPQYPVVPVHLDR, NQNTFLR, and VVLEGGIDPILR.

Selected reaction monitoring mass spectrometry protein assays. Samples were injected $(2 \mu \mathrm{L})$ on the UHPLC system (1260 series Agilent, CA) equipped with an analytical column $\left(\mathrm{C}_{18}\right.$ Peptide $\mathrm{CSH} ; 1.7 \mu \mathrm{m}$, $2.1 \mathrm{~mm}$ i.d. $\times 100 \mathrm{~mm}$; cat. \#186006937; Waters, Milford, MA) thermostated at $40^{\circ} \mathrm{C}$. The mobile phase consisted of solution A $(0.1 \%$ FA in water) and solution B $(0.1 \%$ FA in ACN). The flow rate was $300 \mu \mathrm{L} / \mathrm{min}$, and the gradient elution program consisted of analytical (0-30.9 min) and re-equilibration part (31-35 $\mathrm{min}): 0.0 \mathrm{~min} 5 \%$ B; 25 min 30\% B; 25.5 min 95\% B; 30.9 min 95\% B; 31 min 5\% B; 35 min 5\% B. A standard-flow electrospray was used to couple the UHPLC system with a triple quadrupole mass spectrometer (AJS 6495A, Agilent, CA). Electrospray source operated in positive ion mode (capillary voltage $3.5 \mathrm{kV}$; gas flow rate $11 \mathrm{~L} / \mathrm{min}$ at $130{ }^{\circ} \mathrm{C}$; sheath gas pressure $25 \mathrm{PSI}$ at $400^{\circ} \mathrm{C}$; nozzle voltage $500 \mathrm{~V}$ ). We monitored 98 transitions per the dynamic SRM mode analysis, with 2 min window scheduled around peptide experimental RT. SRM signature transitions were equivalent for proteotypic peptide and corresponding SIL internal standard, i.e., a single SRM quantifier transition and 2-4 additional qualifier SRM transitions were acquired (Table S4).

Protein assay validation and reproducibility. We extracted proteins from all 134 meconium and feces swabs using the protocol and pooled protein extracts $(70 \mu \mathrm{L})$ from all individual samples. We prepared the dilution series adding SIL-TCT or SIL peptides $(10 \mu \mathrm{L})$ into the pooled extract and applied trypsin digestion protocol and UHPLC-SRM. We determined the linearity range, the limit of detection (LOD), the limit of quan- 
tification (LOQ), inter-day and intra-day precision of multiplex SRM protein assay. A dilution series consisted of up to 9 concentration levels, measured at 3-6 technical replicates. A separate calibration curve was used for low abundant ECP and EDN proteins. For interday and intraday reproducibility, protein extracts were prepared at seven concentration levels (i.e., $0.1 ; 0.5 ; 1 ; 2 ; 4 ; 6$, and $8 \mathrm{~g} / \mathrm{l}$ ) in triplicate, processed, and analyzed in three consecutive days ( $\mathrm{n}=6$ each day).

Data analysis. SRM assays were refined using Skyline (Version 19.1.0.193; MacCoss Lab, Uni of Washington, WA). We acquired integrated peak areas in MassHunter (Agilent, CA), performed statistical analysis for method validation using Excel (Microsoft Office Professional Plus, 2013), and performed statistical analyses in GraphPad Prism. LOD and LOQ were determined from the matrix-matched calibration curve. The standard deviation $(\mathrm{SD})$ at the lowest concentration level with a coefficient of variation $(\mathrm{CV})<20 \%(\mathrm{n}=6)$ was used for calculation, e.g., $3^{\star}$ SD divided by SLOPE (for LOD) and $10^{\star}$ SD divided by SLOPE (for LOQ). The coefficient of determinations was $\mathrm{R}^{2}>0.99$, determined using Spearman correlation was performed in GraphPad Prism. Mann-Whitney $U$ test was used for comparison of two groups in GraphPad Prism (Version 8.3.0).

\section{Results and discussion}

Proteolysis reproducibility and peptide yields. The varied amount of neonatal feces collected on a swab is challenging to measure, which hampers the absolute protein quantification. We used the correlation between feces fresh weight (FW) and the total protein content measured by BCA to determine the amount of stool collected on a swab (Figure S1 and Table S3). We tested the reproducibility of trypsin digestion after 1, $3,5,17,20$, and $24 \mathrm{~h}$ of incubation using QC sample protein extracts with added SIL-TCT peptides. Peptide concentrations and CV $(\mathrm{n}=3)$ were determined (Table S5). Surrogate peptides were not detected in the control sample ( $0 \mathrm{~h}$, no trypsin added). The surrogate peptides' yields were optimal within $5 \mathrm{~h}$ of incubation; $\mathrm{CV}<16.7 \%$ (Figure S2).

Validation of multiplex protein assay. Protein assays for A1AT-1, IGHA1, IGHA2, IGHA1 + 2, ECP, EDN, MPO, CAL1, and CAL2 were validated using matrix-matched calibration curves for each SIL-TCT peptide standard in terms of linearity of response, $\mathrm{R}^{2}, \mathrm{LOD}$, and LOQ. Protein assays were linear within the range of two orders of magnitude at minimum, typically from 0.04 to $14.77 \mu \mathrm{g} / \mathrm{mg}$ of the total protein content. All $\mathrm{R}^{2}$ were $>0.99$. LODs and LOQs of target proteins in the sample matrix ranged from 0.003 to $0.04 \mu \mathrm{g} / \mathrm{mg}$ and from 0.009 to $0.122 \mu \mathrm{g} / \mathrm{mg}$ of total protein content, respectively (Table 2).

We established the intra- and inter-day precision in QC samples within a single day $(n=6)$ and three consecutive days $(n=6)$. The intraday median $\mathrm{CV}$ precision was $9.8 \%$; all $\mathrm{CV}$ values $<17.8 \%$ (Table S6). The interday median CV precision was $14.1 \%$, all CV values $<16.2 \%$, except for peptide TPLTATLSK (IGHA1) with the CV of $28.9 \%$ (Table S7). The peptide VVLEGGIDPILR (MPO) concentration in the QC sample was below LOQ $(29.9 \% \mathrm{CV})$.

Robustness of multiplex protein assays. Meconium or feces FW collected on a swab ranged between 25 and $150 \mathrm{mg}$, corresponding to $0.97-10.34 \mu \mathrm{g} / \mu \mathrm{L}$ of extracted total protein concentration. The extraction efficiency or kinetics of trypsin digestion and overall protein assay accuracy may be affected by variable protein concentration in extracts. We tested the robustness of A1AT-1, IGHA1, IGHA2, IGHA1 + 2, ECP, EDN, MPO, CAL1, and CAL2 quantification in QC sample stool extracts varied in total protein concentration (i.e., 0.1; 0.5; $1 ; 2 ; 4 ; 6$ and $8 \mu \mathrm{g} / \mu \mathrm{L}$, range $5-400 \mu \mathrm{g} / 50 \mu \mathrm{L}$ of extract). The assay was robust as all protein concentrations were determined within CV $<20.6 \%$ (Table S8 and Figure S3), except for low abundant EDN (CV 25.1\%).

Immune markers in meconium and feces. Meconium initially excreted by neonates transitions into a first feces around the second day after birth due to breastfeeding ${ }^{32}$. We quantified fecal IGHA1 and IGHA2 levels introduced from breast milk to capture the transition and differentiate meconium and first feces samples. We classified 64 samples as meconium (IGHA $<10 \mu \mathrm{g} / \mathrm{mg}$ of total protein) and 70 samples as the first feces (IGHA $>10 \mu \mathrm{g} / \mathrm{mg}$ of total protein). We compared levels of immune markers in meconium $(\mathrm{n}=64)$ and feces $(\mathrm{n}=70)$ samples with the Mann-Whitney $U$ test (Fig. 2). We found significantly higher A1AT-1, CAL1, CAL2, ECP, and MPO levels in meconium relative to feces $(\mathrm{P}<0.0001)$. Higher levels of blood plasma-derived A1AT- 1 (Fig. 2A) in meconium indicate permeability of immature intestinal barrier for plasma proteins and blood cells $\mathrm{s}^{39}$. The breast milk consumption induces the tightening of intestinal barrier function and reduces blood proteins' leakage into the feces ${ }^{32}$. The initial colonization by gut microbiota, enhanced by breast milk intake, causes the release of MPO from neutrophils attacking bacteria ${ }^{17}$. Presumably, a reason for significantly higher MPO levels in feces compared to meconium $(\mathrm{P}<0.0001)$.

The breast milk intake probably contributes to allergic sensitization ${ }^{40}$. ECP and EDN from eosinophils play a role in the host defense against a pathogen ${ }^{41}$. ECP and EDN have an antiviral activity to single strained RNA viruses $^{42}$. ECP has marked antibacterial activity and toxicity for helminth parasites. On the other hand, EDN activates dendric cells to express inflammatory chemokines and cytokines, activates the TLR2- MyD88 signal pathway, and enhances Th2 immune responses ${ }^{43}$. The presence of ECP and EDN released from blood-born eosinophils in the intestinal lumen indicates endogenous allergic inflammation ${ }^{22,31}$. While we determined significantly increased ECP levels in the first feces relative to meconium, the increase of EDN was not significant (Fig. 2). Perhaps, a consequence of the permeable intestine on the first day of life, allowing for a massive nonspecific infiltration of meconium by other white blood cells expressing EDN (e.g., basophils and neutrophils) ${ }^{44}$. In consecutive days of life, the intestine permeability decreases, allowing only eosinophils to infiltrate and contribute to fecal EDN. We cross-compared ECP and EDN levels in meconium and feces to assess other white blood cells' 

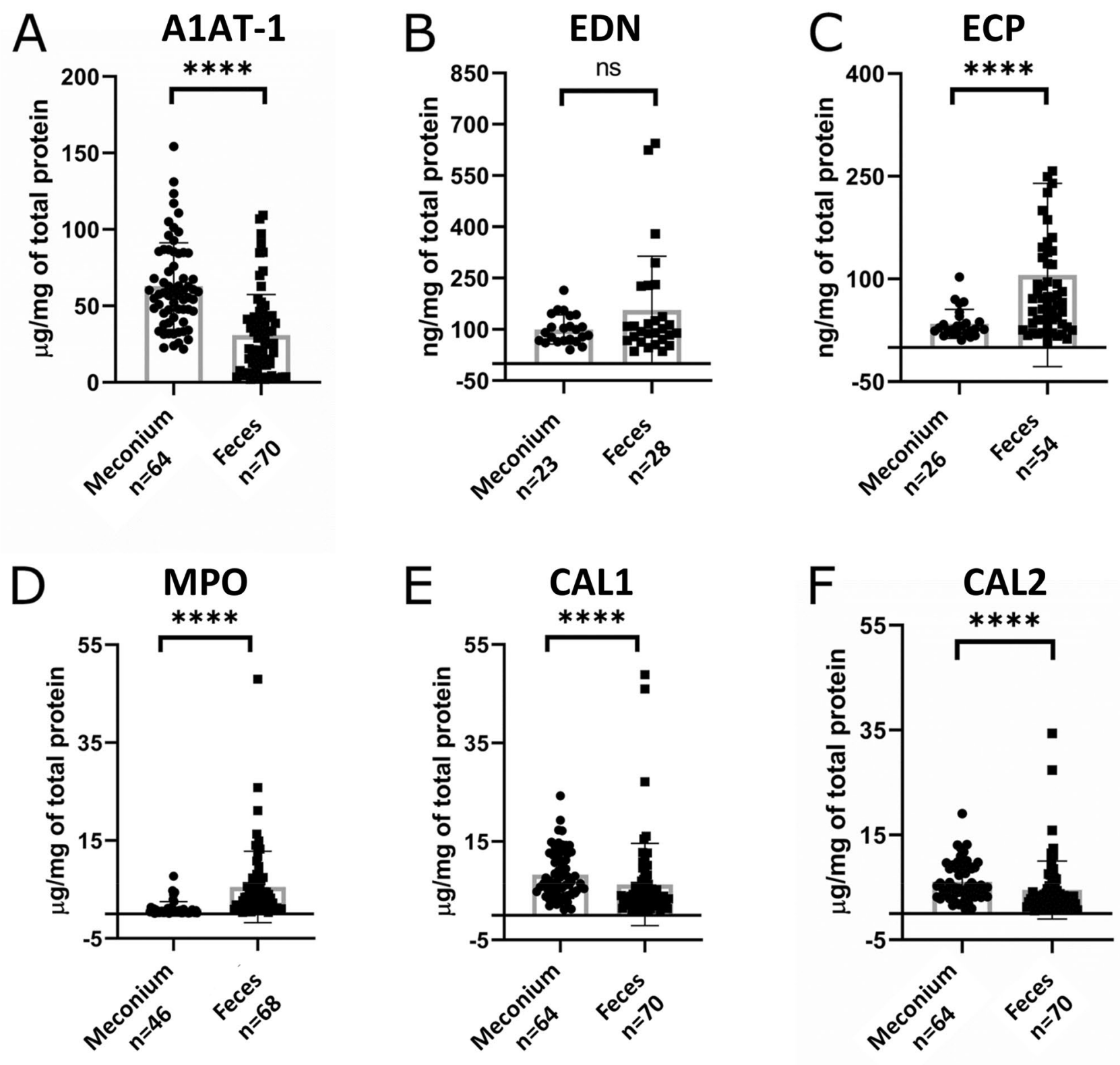

Figure 2. Levels of immune protein markers in meconium and feces: (A) A1AT-1, (B) EDN, (C) ECP, (D) MPO, (E) CAL1, (F) CAL2. Mann-Whitney $U$ test ${ }^{* * * *} P<0.0001$.

potential contribution to meconium EDN (Fig. 3). If ECP and EDN in meconium and feces are derived only from eosinophils, the EDN/ECP ratio in meconium and feces is expected similar. The EDN/ECP ratio in meconium was substantially higher than in the first feces suggesting a contribution from other white blood cells to the total meconium EDN level. However, the different EDN/ECP ratios may also reflect changes in eosinophil protein expression after the first day of life.

A1AT-1, IGHA1, IGHA2, IGHA1 + 2, ECP, EDN, MPO, CAL1, and CAL2 levels (Table S2) in meconium and feces $(n=134)$, sorted by decreasing concentration of IGHA were cross-correlated using the Spearman correlation factor (Fig. 4). The excretory IGHA1 +2 in feces and meconium negatively correlated with A1AT-1 (Spearman correlation factor of - 0.6), as previously reported ${ }^{32}$. Li et al. demonstrated decreasing calprotectin levels in neonatal stool between 1 to 18 months ${ }^{45}$. Indeed, we detected a negative correlation of IGHA $1+2$ with both CAL1 and CAL2 (Spearman correlation factor of - 0.4). MPO and ECP moderately correlate with IGHA1 + 2 (Spearman correlation factor of 0.67 and 0.59 , respectively). MPO was associated with ECP (Spearman correlation factor of 0.72 ) and ECP with EDN (Spearman correlation factor of 0.63 ).

Birth mode influence on immune protein levels in meconium and feces. Meconium and feces samples were from neonates delivered vaginally (VD) and via cesarean section (CS). VD reportedly fosters the 

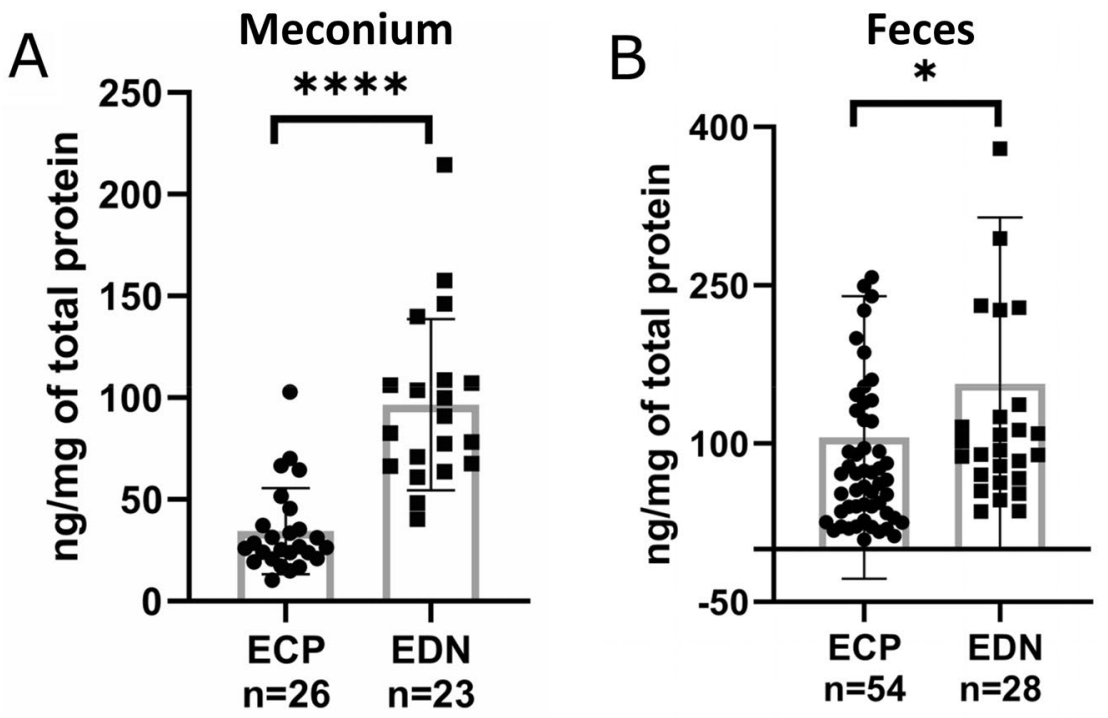

Figure 3. ECP and EDN levels in meconium and feces. (A) meconium $(n=41)$ and (B) feces $(n=70)$, MannWhitney $U$ test, ${ }^{\star} P<0.05,{ }^{* * *} P<0.0001$.

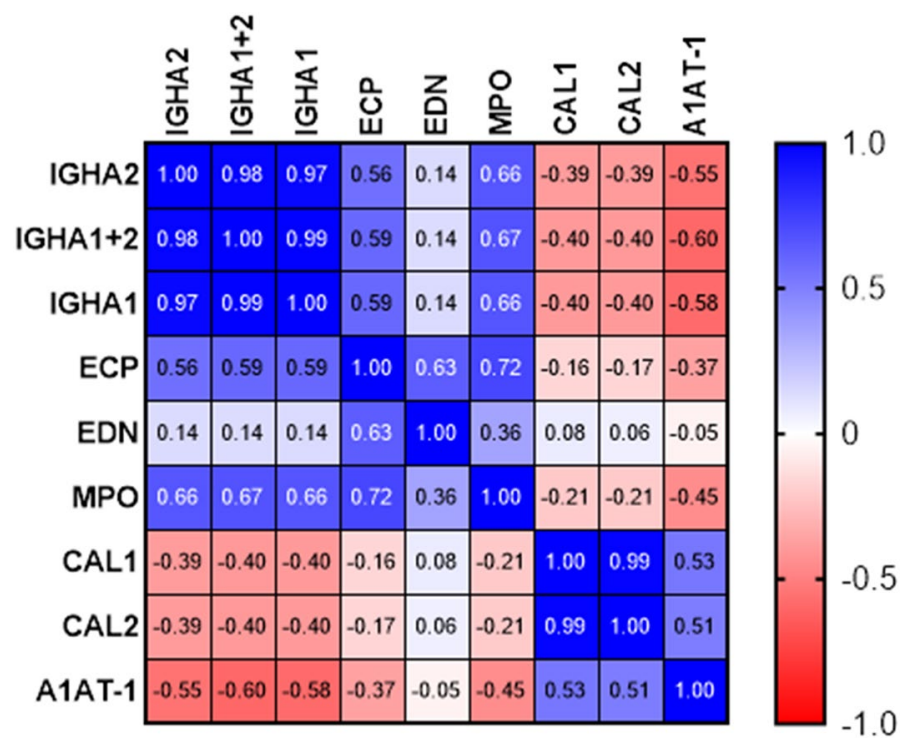

Figure 4. Correlation matrix plot for IGHA, A1AT-1, IGHA1, IGHA2, IGHA1 +2, ECP, EDN, MPO, CAL1, and CAL2 levels in neonatal stool samples $(\mathrm{n}=134)$.

eubiotic bacterial colonization of the intestinal lumen ${ }^{46}$. Conversely, skin commensals, opportunistic pathogens, or nosocomial bacteria primarily colonize CS neonates' intestinal lumen. CAL1 and CAL2 levels indicate the neutrophil type of inflammation in response to a pathogen's presence in the intestinal lumen ${ }^{17}$. The comparison of CAL1 and CAL2 levels in the feces of VD $(n=58)$ and CS $(n=12)$ neonates revealed significantly higher CAL1 levels ( $P$ value 0.0439 ) in CS neonates (Figure S4). CAL1 and CAL2 are components of the calprotectin dimer complex, but the CAL2 level was not significantly different between CS and VD neonates ( $P$ value 0.0622$)$. However, fecal calprotectin levels were highly varied in neonates, and the sample size was limited. Meconium CAL1 and CAL2 in CS and VD neonates were not significantly different (Figure S4). Increased fecal calprotectin is a potential marker of dysbiosis and low-grade inflammation of the gastrointestinal tract in CS neonates. 


\section{Conclusions}

In summary, we developed and validated a multiplex mass spectrometry-based protein assay for absolute quantification of adaptive immunity effectors (i.e., IGHA1, IGHA2) and immune protein markers (i.e., A1AT, ECP, EDN, MPO, CAL1, CAL2) in neonatal meconium and feces swabs. While circulating immune protein markers are routinely quantified in blood/serum, neonatal excretory levels are not established. We determined the stool (fresh weight) collected on a swab by measuring protein concentration in protein extracts. Information on the precise amount collected on a stool swab is required for absolute protein quantification. Breast milk-derived IGHA2 differentiates meconium from feces to study the influence of breastfeeding on intestinal barrier function maturation. Absolute quantification of multiple immune protein markers characterizes the type of inflammation in the intestinal lumen. We found significantly higher fecal calprotectin levels in neonates delivered via Cesarean section relative to vaginal delivery birth. The finding may indicate a low-grade inflammation in response to microbial dysbiosis in CS neonates.

\section{Data availability}

The mass spectrometry data were deposited to the PANORAMA Repository (https://panoramaweb.org/U\% 20of\%20Masaryk\%20-\%20RECETOX/Vidova_MultiMec_Assay/project-begin.view?pageId=Raw\%20Data).

Received: 29 January 2021; Accepted: 26 April 2021

Published online: 13 May 2021

\section{References}

1. Alatab, S. et al. The global, regional, and national burden of inflammatory bowel disease in 195 countries and territories, 1990-2017: A systematic analysis for the Global Burden of Disease Study 2017. Lancet Gastroenterol. Hepatol. 5, 17-30 (2020).

2. Loh, W. \& Tang, M. The epidemiology of food allergy in the global context. Int. J. Environ. Res. Public Health 15, 2043 (2018).

3. Singh, P. et al. Global prevalence of celiac disease: Systematic review and meta-analysis. Clin. Gastroenterol. Hepatol. 16, 823-836. e2 (2018).

4. Tordesillas, L., Berin, M. C. \& Sampson, H. A. Immunology of food allergy. Immunity 47, 32-50 (2017).

5. Sicherer, S. H. \& Sampson, H. A. Food allergy: A review and update on epidemiology, pathogenesis, diagnosis, prevention, and management. J. Allergy Clin. Immunol. 141, 41-58 (2018).

6. Danese, S., Sans, M. \& Fiocchi, C. Inflammatory bowel disease: the role of environmental factors. Autoimmun. Rev. 3, 394-400 (2004).

7. Park, J. H., Peyrin-Biroulet, L., Eisenhut, M. \& Shin, J. I. IBD immunopathogenesis: A comprehensive review of inflammatory molecules. Autoimmun. Rev. 16, 416-426 (2017).

8. Kelly, D., King, T. \& Aminov, R. Importance of microbial colonization of the gut in early life to the development of immunity. Mutat. Res. Fundam. Mol. Mech. Mutagen. 622, 58-69 (2007).

9. McKenzie, C., Tan, J., Macia, L. \& Mackay, C. R. The nutrition-gut microbiome-physiology axis and allergic diseases. Immunol. Rev. 278, 277-295 (2017)

10. Miyoshi, J. \& Chang, E. B. The gut microbiota and inflammatory bowel diseases. Transl. Res. 179, 38-48 (2017).

11. Olszak, T. et al. Microbial exposure during early life has persistent effects on natural killer T cell function. Science 336, 489-493 (2012).

12. Cox, L. M. et al. Altering the intestinal microbiota during a critical developmental window has lasting metabolic consequences. Cell 158, 705-721 (2014)

13. Thavagnanam, S., Fleming, J., Bromley, A., Shields, M. D. \& Cardwell, C. R. A meta-analysis of the association between Caesarean section and childhood asthma. Clin. Exp. Allergy 38, 629-633 (2008).

14. Sevelsted, A., Stokholm, J., Bønnelykke, K. \& Bisgaard, H. Cesarean section chronic immune disorders. Pediatrics 135, e92-e98 (2015).

15. Oddy, W. H. Breastfeeding, childhood asthma, and allergic disease. Ann. Nutr. Metab. 70, 26-36 (2017).

16. Lee, J. et al. Molecular pathophysiology of epithelial barrier dysfunction in inflammatory bowel diseases. Proteomes 6, 17 (2018).

17. Langhorst, J. et al. Noninvasive markers in the assessment of intestinal inflammation in inflammatory bowel diseases: Performance of fecal lactoferrin, calprotectin, and PMN-elastase, CRP, and clinical indices. Am. J. Gastroenterol. 103, 162-169 (2008).

18. Saiki, T. Myeloperoxidase concentrations in the stool as a new parameter of inflammatory bowel disease. Kurume Med. J. 45, 69-73 (1998).

19. Masoodi, I. et al. Evaluation of fecal myeloperoxidase as a biomarker of disease activity and severity in ulcerative colitis. Dig. Dis. Sci. 57, 1336-1340 (2012).

20. Lisowska-Myjak, B., Zytyńska-Daniluk, J. \& Skarzyńska, E. Concentrations of neutrophil-derived proteins in meconium and their correlations. Biomark. Med. 10, 819-829 (2016).

21. Ohtsuka, Y. Food intolerance and mucosal inflammation. Pediatr. Int. 57, 22-29 (2015).

22. Kalach, N. et al. Intestinal permeability and fecal eosinophil-derived neurotoxin are the best diagnosis tools for digestive non-IgEmediated cow's milk allergy in toddlers. Clin. Chem. Lab. Med. 51, 351-361 (2013).

23. Bridgman, S. L. et al. Infant gut immunity: a preliminary study of IgA associations with breastfeeding. J. Dev. Orig. Health Dis. 7 , 68-72 (2016).

24. Test ID: FECP, Eosinophil Cationic Protein (ECP), Fluoroenzyme Immunoassay. https://www.mayocliniclabs.com/test-catalog/ Overview/57809.

25. Kosek, M. et al. Fecal markers of intestinal inflammation and permeability associated with the subsequent acquisition of linear growth deficits in infants. Am. J. Trop. Med. Hyg. 88, 390-396 (2013).

26. Skarżyńska, E., Żytyńska-Daniluk, J. \& Lisowska-Myjak, B. Correlations between ceruloplasmin, lactoferrin and myeloperoxidase in meconium. J. Trace Elem. Med. Biol. 43, 58-62 (2017).

27. Roca, M. et al. Fecal calprotectin and eosinophil-derived neurotoxin in healthy children between 0 and 12 years. J. Pediatr. Gastroenterol. Nutr. 65, 394-398 (2017).

28. Test ID: CALPR, Calprotectin, Feces, Enzyme-Linked Immunosorbent Assay (ELISA).

29. Test ID: AATP, Alpha-1-Antitrypsin, Nephelometry.

30. Skarżyńska, E., Kiersztyn, B., Wilczyńska, P., Jakimiuk, A. \& Lisowska-Myjak, B. Total proteolytic activity and concentration of alpha-1 antitrypsin in meconium for assessment of the protease/antiprotease balance. Eur. J. Obstet. Gynecol. Reprod. Biol. 223, 133-138 (2018).

31. Saarinen, K. M., Sarnesto, A. \& Savilahti, E. Markers of inflammation in the feces of infants with cow's milk allergy. Pediatr. Allergy Immunol. 13, 188-194 (2002). 
32. Lisowska-Myjak, B. \& Pachecka, J. Alpha-1-antitrypsin and IgA in serial meconium and faeces of healthy breast-fed newborns. Fetal Diagn. Ther. 22, 116-120 (2007).

33. Vidova, V. \& Spacil, Z. A review on mass spectrometry-based quantitative proteomics: Targeted and data independent acquisition. Anal. Chim. Acta 964, 7-23 (2017).

34. Picotti, P., Bodenmiller, B. \& Aebersold, R. Proteomics meets the scientific method. Nat. Methods 10, 24-27 (2012).

35. Henderson, C. M. et al. Quantification by nano liquid chromatography parallel reaction monitoring mass spectrometry of human apolipoprotein A-I, apolipoprotein B, and hemoglobin Alc in dried blood spots. Proteom. Clin. Appl. 11, 1600103 (2017).

36. Singh, R. J., Hines, J. M., Lopez, M. F., Krastins, B. \& Hoofnagle, A. N. Mass spectrometric immunoassay raises doubt for the existence of parathyroid hormone fragment 7-84. Clin. Chem. 61, 558-560 (2015).

37. Gopalakrishna, K. P. \& Hand, T. W. Influence of maternal milk on the neonatal intestinal microbiome. Nutrients 12, 823 (2020).

38. Schnatbaum, K. et al. New approaches for absolute quantification of stable-isotope-labeled peptide standards for targeted proteomics based on a UV active tag. Proteomics 20, 2000007 (2020).

39. Tibble, J. A., Sigthorsson, G., Bridger, S., Fagerhol, M. K. \& Bjarnason, I. Surrogate markers of intestinal inflammation are predictive of relapse in patients with inflammatory bowel disease. Gastroenterology 119, 15-22 (2000).

40. Martín-Muñoz, M. F. et al. Food allergy in breastfeeding babies. Hidden allergens in human milk. Eur. Ann. Allergy Clin. Immunol. 48, 123-128 (2016).

41. Boix, E. et al. Structural determinants of the eosinophil cationic protein antimicrobial activity. Biol. Chem. 393, 801-815 (2012).

42. Acharya, K. R. \& Ackerman, S. J. Eosinophil granule proteins: Form and function. J. Biol. Chem. 289, 17406-17415 (2014).

43. Yang, D. et al. Eosinophil-derived neurotoxin acts as an alarmin to activate the TLR2-MyD88 signal pathway in dendritic cells and enhances Th2 immune responses. J. Exp. Med. 205, 79-90 (2008).

44. Abu-Ghazaleh, R. I. et al. Eosinophil granule proteins in peripheral blood granulocytes. J. Leukoc. Biol. 52, 611-618 (1992).

45. Li, F. et al. Fecal Calprotectin concentrations in healthy children aged 1-18 months. PLoS ONE 10, e0119574 (2015).

46. Houghteling, P. D. \& Walker, W. A. Why is initial bacterial colonization of the intestine important to infants' and children's health?. J. Pediatr. Gastroenterol. Nutr. 60, 294-307 (2015).

\title{
Acknowledgements
}

This work supported by the Grant Agency of the Czech Republic (Project No. 17-24592Y; Z.S.), Research Infrastructure RECETOX RI (No LM2018121) financed by the Ministry of Education, Youth and Sports, and Operational Programme Research, Development, and Innovation-project CETOCOEN EXCELLENCE (No CZ.02.1.0 1/0.0/0.0/17_043/0009632), Czech Republic_conceptual research organization development (FNBr, 65269705; J.K.). Many thanks to the participating medical staff of University Hospital Brno, St. Anne's University Hospital, and the entire study team.

\section{Author contributions}

V.V. performed laboratory experiments, acquired and processed mass spectrometry data, and drafted the manuscript; E.B. participated in the laboratory experiments and data analysis; J.K. participated in the study design; V.T. advised in study design and data interpretation; Z.S. designed the study, advised on the data interpretation, and wrote the manuscript. All authors reviewed and approved the final version of the manuscript.

\section{Competing interests}

The authors declare no competing interests.

\section{Additional information}

Supplementary Information The online version contains supplementary material available at https://doi.org/ 10.1038/s41598-021-89384-0.

Correspondence and requests for materials should be addressed to Z.S.

Reprints and permissions information is available at www.nature.com/reprints.

Publisher's note Springer Nature remains neutral with regard to jurisdictional claims in published maps and institutional affiliations.

\begin{abstract}
Open Access This article is licensed under a Creative Commons Attribution 4.0 International License, which permits use, sharing, adaptation, distribution and reproduction in any medium or format, as long as you give appropriate credit to the original author(s) and the source, provide a link to the Creative Commons licence, and indicate if changes were made. The images or other third party material in this article are included in the article's Creative Commons licence, unless indicated otherwise in a credit line to the material. If material is not included in the article's Creative Commons licence and your intended use is not permitted by statutory regulation or exceeds the permitted use, you will need to obtain permission directly from the copyright holder. To view a copy of this licence, visit http://creativecommons.org/licenses/by/4.0/.
\end{abstract}

(C) The Author(s) 2021 